\title{
The effect of crash experience on changes in risk taking among urban and rural young people
}

\author{
Mau-Roung Lin ${ }^{\mathrm{a}, *}$, Wenzheng Huang ${ }^{\mathrm{b}}$, Hei-Fen Hwang ${ }^{\mathrm{c}}$, \\ Hong-Dar Isaac $\mathrm{Wu}^{\mathrm{d}}$, Lee-Lan Yen ${ }^{\mathrm{e}}$ \\ ${ }^{a}$ Institute of Injury Prevention and Control, Taipei Medical University, 250 Wu-Hsing St., Taipei 110, Taiwan, ROC \\ ${ }^{\mathrm{b}}$ Department of Biostatistics, Harvard School of Public Health, 655 Huntington Ave., Boston, MA 01701, USA \\ ${ }^{\mathrm{c}}$ Department of Nursing, National Taipei College of Nursing, 365 Ming-Te Rd., Taipei 112, Taiwan, ROC \\ ${ }^{\mathrm{d}}$ School of Public Health, China Medical College, 91 Hsueh-Shih Rd., Taichung 404, Taiwan, ROC \\ ${ }^{\mathrm{e}}$ College of Public Health, Institute of Health Policy and Management, National Taiwan University, Rm. 1522, No. 1, \\ Jen-Ai Rd., Sec. 1, Taipei 100, Taiwan, ROC
}

Received 11 July 2002; received in revised form 19 November 2002; accepted 21 November 2002

\begin{abstract}
A 20-month prospective study was conducted to investigate the effect of motorcycle crash experience on changes in risk taking among 2514 urban and 2304 rural students in Taiwan. Risk taking was assessed using a 14-item self-administered questionnaire at the beginning and end of the study. A risk-taking score for each student at the initial and the last follow-up assessments was generated from adding up points across all 14 items. For exposure variables, the study documented past motorcycle crash history at the initial assessment and collected detailed information about any motorcycle crash involvement that occurred during the study period. A general linear mixed model was applied to assess the effects of prior and recent crash involvements on the path of risk-taking behavior. The results show that at the initial assessment, students with crash experience had higher risk-taking levels than those without crash experience. However, crash experience, irregardless of whether it was measured in terms of crash history prior to the study, crash frequency, time elapsed since the last crash, or crash severity, did not significantly change the risk-taking path among students, even though its effect differed between urban and rural areas.
\end{abstract}

(C) 2003 Elsevier Science Ltd. All rights reserved.

Keywords: Crash; Epidemiology; Motorcycle; Risk taking; Taiwan; Young people

\section{Introduction}

Risk taking has been identified as a critical contribution to the occurrence of many health problems such as motor-vehicle crashes (Jelalian et al., 2000; Sells and Bhon, 1996; Schootman et al., 1993; Alexander et al., 1992; Slap et al., 1991; Brown et al., 1986; Jonah, 1986), sexually transmitted diseases, pregnancy, criminal violence, and substance abuse among young people (Sells and Bhon, 1996; Greydanus, 1987; Tokin, 1987; Irwin and Millstein, 1986). In addition to physical problems, it can be also linked to a number of biological markers of psychological function (Zuckerman, 1990; Tarter et al., 1985). Therefore, knowledge of how levels of risk taking can be altered by personal experience is a key to reducing these health problems in

\footnotetext{
* Corresponding author. Tel.: +886-2-27390217; fax: +886-2-27390387.

E-mail address: mrlin@tmu.edu.tw (M.-R. Lin).
}

young people (Weinstein and Klein, 1996; Perloff and Fetzer, 1986).

Several studies have reported that involvement in motor-vehicle crashes increases the perceived risk of future crashes (Rutter et al., 1998; Matthews and Moran, 1986; Sevenson et al., 1985); however, health-promotion programs using negative consequences of motor-vehicle crashes as educational materials with the goal of reducing motor-vehicle injuries often fail to change risk-taking levels (Ray et al., 1982; Hill and Jamieson, 1978; Preusser et al., 1976; Shaoul, 1975). In contrast, several studies have reported that adolescent drivers who have experienced a motor-vehicle crash are at a greater risk of subsequent crashes as compared to those who have not (Begg et al., 1999; Slap et al., 1991). It seems that adolescents who perceive a higher risk after experiencing a crash do not adopt precautionary behaviors or do not reduce their risk-taking levels. Nevertheless, to our knowledge, no empirical evidence on the relationship between personal crash experience and 
changes in risk-taking levels among young people has been provided.

We conducted a 20 -month prospective study to examine the relationships among frequency, severity of crash involvement, and time elapsed since the most recent crash occurring in the study period as well as crash history prior to the study to changes in risk-taking levels among urban and rural junior college students in Taiwan. This study only focused on experience related to motorcycle crashes because motorcycles comprise $73 \%$ of the registered motor vehicles (MCT, 1993) and are the dominant mode of transportation among young people in Taiwan. Furthermore, immense public health implications from this issue are expected since motorcycle injuries are one of the most serious problems among young persons in many countries (Liberatti et al., 2001; Pang et al., 2000; Begg et al., 1994; Swaddiwudhipong et al., 1994; Ding et al., 1993; Mohan and Bawa, 1985).

\section{Materials and methods}

\subsection{Study population}

The study was conducted using students from three junior colleges in Taipei and Hualien. Students attending junior colleges in Taiwan usually complete a series of 5 grades before graduation, and the average entry age is about 15 years. Junior college students were selected because: (1) they are an identifiable cohort at high risk of motorcycle injuries, and (2) these students have detailed school records and are easier to follow up. The two areas, Taipei and Hualien, were chosen because they best represent the heterogeneity of demographical profiles and transportation patterns in Taiwan. While Taipei is highly urbanized, Hualien is predominately rural. There were eight junior colleges in Taipei and three in Hualien at the time of this study. Two junior colleges were randomly selected from each of the two areas, but one of the selected junior colleges in Taipei declined to participate in the study. Students initially in the first and second years were excluded from the study because they were generally not old enough to qualify for a license to operate a motorcycle at that time (the age of licensure is 18 years in Taiwan).

One initial and three subsequent follow-up assessments were carried out at about 6-month intervals during the 20-month study period from November 1994 to June 1996. Of 4721 eligible students initially enrolled in the three schools, 4463 completed the initial assessment, but only 3407 completed the third follow-up, as 938 students had graduated before the second follow-up assessment. In this study, response rates ranged from $90 \%$ in the third follow-up assessment to $95 \%$ in the initial one, with an overall average of $92 \%$ for all four assessments. Of these respondents, the percentage of students that had ridden a motorcycle at least once in the month prior to each assessment ranged from $82 \%$ in the initial assessment to $91 \%$ in the second follow-up, with an overall average of $87 \%$.

\subsection{Exposure assessment}

\subsubsection{Baseline characteristics}

Characteristics measured in the initial assessment included type of residential area, age, gender, socioeconomic status based on parental education and income, whether living at home, usual riding position (operator or passenger), riding experience, frequency of usual alcohol consumption, and history of motorcycle crashes prior to the study. In this study, a motorcycle crash was defined as an occurrence for which the operator or at least one rider had fallen down onto the road either in a single- or multiple-vehicle collision.

\subsubsection{Motorcycle crashes over the study period}

Information on motorcycle crashes that occurred during the study period was mainly reported through class representatives elected by students. Students were asked to report any crashes occurring in the past week to their representatives at a weekly class meeting. Study staff also contacted the representatives by telephone every 2 weeks to remind them to report any motorcycle crashes that had occurred in the previous 2 weeks. In addition, at each follow-up assessment visit, the study staff asked students how many crashes had not been reported to the representatives since the previous assessment. School records were also examined monthly for severe crashes that may not have been reported. It is compulsory for schools in Taiwan to record any severe injuries, such as those requiring hospitalization and those resulting in fatalities.

Three measures were used to assess crash experience which occurred during the study period: the number of motorcycle crashes, the time elapsed since the most recent crash, and the severity of the most serious crash. Here, crash severity was classified into two levels as non-injury and injury; an injury was characterized by an occurrence when the student survived the crash but sought medical care, was hospitalized, or later died from the crash.

\subsection{The risk-taking scale}

\subsubsection{Construction}

Risk taking in this study refers to potentially harmful behaviors that young people engage in with or without understanding the immediate or long-term consequences of their actions (Irwin and Millstein, 1986). A study-specific self-administered questionnaire was constructed to measure the degree to which a youth engaged in risk-taking behaviors. Two focus group sessions and one pretest were conducted to identify possible items to use when constructing such a questionnaire. In the first focus group session, a discussion was held among six health-related professionals, including a sociologist, epidemiologist, psychologist, pharmacist, nurse, and public health worker, and eight items were suggested for describing risk-taking behaviors. These items were video game playing at arcades, cigarette smoking, jaywalking, skipping class, betel nut chewing, drinking and driving, 
cheating on examinations, and engaging in sexual activities. It is worth mentioning that the relevance of these items must be viewed in the context of local social norms. For example, video game playing was included because, at that time, minors were prohibited by law from playing. After the first focus group session, a pretest was conducted in which 94 junior college students were requested to write down their comments on whether these eight items were appropriate to describe risk taking among young people and to suggest any additional items that might be added. Immediately after the pretest, a second focus group with six volunteer students further discussed the 94 students' comments and suggested items for revision. It was generally agreed that all eight items suggested by the first focus group session were appropriate. Furthermore, six additional items, including using foul language, motorcycle/car racing on roads, going to pubs/bars, verbal fighting, physical fighting, and gambling, were added. As a result, a total of 14 items was used to construct a risk-taking scale for junior college students in the study.

Risk taking by participating students was measured twice using this questionnaire. The first measure was obtained in the initial assessment at the beginning of the study and the second in the third follow-up assessment at the end of the study. In the self-administered questionnaire, each of the 14 items was given a recall time period ranging from 2 weeks to 1 year, depending on how often that item possibly occurred. Furthermore, a 4-point frequency response scale for each item was provided. A risk-taking score for each individual student at each of the two assessments was accordingly generated from adding the points across all 14 items, ranging from 0 (no risk-taking propensity) to 42 (the highest level of risk taking). The average score was 4.4 and 5.1 at the initial and the third follow-up assessments, respectively.

\subsubsection{Psychometric properties}

The risk-taking scale, on the whole, demonstrated good psychometric properties on a variety of reliability and validity parameters (Nunnally and Bernstein, 1994), and therefore, it was adequate to measure the risk-taking levels among the junior college students. Cronbach's $\alpha$ of the 14 items in the initial and the third follow-up assessments ranged from 0.71 to 0.76 , indicating good internal consistency. In addition, the test-retest reliability of the 14-item scale was in substantial agreement. Of 300 students randomly selected from the study population, 272 were personally interviewed to validate their original questionnaire responses within 2 weeks of completing the questionnaire in the initial assessment. Intraclass correlation coefficients for the 14 items ranged from 0.63 to 0.92 . Convergent validity of the risk-taking scale was validated by factor analysis. The results from two criteria, factor eigenvalues (>1) and scree test (Stevens, 1992), consistently indicated that only one common factor or a single risk-taking scale should be adequate to represent the 14 items. Moreover, factor loadings and the construction of a single common factor were also consistent across the initial and the third follow-up assessments, the only two assess- ments where risk-taking questionnaires were administered. Finally, to verify the discriminative and predictive validity of the computed risk-taking scores, we compared the mean risk-taking scores between students with and without motorcycle crashes prior to the study and between students with and without motorcycle crashes during the study period. Differences in these mean risk-taking scores were statistically significant.

\subsection{Statistical analysis}

Changes in risk-taking scores from the initial to the follow-up assessment within baseline characteristics and crash experience measures by residential area were also compared, using one-way analysis of variance (ANOVA). Furthermore, to account for this correlation among the repeated risk-taking measures for a student due to some unobserved individual human or environmental factors, we used the linear mixed model (Cnaan et al., 1997; Diggle et al., 1994) to estimate how risk-taking measures changed over time and how this course depended on multiple potential factors. One advantage of using the mixed model is that it allows estimation of individual paths of risk taking and the average of these paths. In linear mixed models, random intercepts and the unstructured covariance were specified. Students in Taipei and Hualien were analyzed separately because the effect of crash experience on risk taking appeared to somewhat differ between the two groups in the primary analysis. Furthermore, for each group, three different models were fitted depending on the covariates used for measuring crash experience during the study period (i.e. crash frequency, time elapsed since the last crash, and crash severity) to avoid collinearity among the three measures. In the initial multivariate analysis of the linear mixed model, variables with a $P$-value of less than 0.25 in the univariate analysis were included (Mickey and Greenland, 1989). We eliminated potential confounders from the final linear mixed model which did not cause important changes in the adjusted mean differences in interaction terms of crash experience measures with time.

The regression coefficients of crash experience measures in the linear mixed model can be interpreted as the adjusted mean differences in risk-taking scores among the levels of crash experience at the time of the initial assessment. Furthermore, the regression coefficients of crash experience measures interacting with time can be interpreted as changes in risk-taking scores from the initial to the follow-up assessment among levels of crash experience. In the study, Statistical Analysis Software (SAS) version 6.12 was used for all statistical analyses.

\section{Results}

Table 1 presents the number and percentage of $4463 \mathrm{ju}-$ nior college students, 2154 in Taipei and 2309 in Hualien, 
Table 1

Distributions of baseline characteristics and crash history prior to the study among 2154 junior college students in Taipei and 2309 in Hualien, Taiwan

\begin{tabular}{|c|c|c|c|}
\hline Characteristic & Total $(n=4463)($ no. $(\%))$ & Taipei $(n=2154)($ no. $(\%))$ & Hualien $(n=2309)$ (no. $(\%))$ \\
\hline \multicolumn{4}{|l|}{ Age at the initial assessment (years) } \\
\hline 17 & $544(12.2)$ & $389(18.1)$ & $155(6.7)$ \\
\hline 18 & $1795(40.2)$ & $1046(48.4)$ & $749(32.4)$ \\
\hline 19 & $1402(31.4)$ & $559(26.0)$ & $843(36.5)$ \\
\hline$\geq 20$ & $722(16.2)$ & $160(7.4)$ & $562(24.3)$ \\
\hline \multicolumn{4}{|l|}{ Gender } \\
\hline Female & $3033(68.0)$ & $1384(64.3)$ & $1649(71.4)$ \\
\hline Male & $1430(32.0)$ & $770(35.8)$ & $660(28.6)$ \\
\hline \multicolumn{4}{|l|}{ Father's education } \\
\hline Elementary or below & $1481(33.4)$ & $667(31.1)$ & $814(35.6)$ \\
\hline Junior high & $972(21.9)$ & $457(21.3)$ & $515(22.5)$ \\
\hline Senior high & $1183(26.7)$ & $581(27.1)$ & $602(26.3)$ \\
\hline College or above & $798(18.0)$ & $440(20.5)$ & $358(15.6)$ \\
\hline \multicolumn{4}{|l|}{ Mother's education } \\
\hline Elementary or below & $2358(53.2)$ & 1059 (49.4) & $1299(56.8)$ \\
\hline Junior high & $907(20.5)$ & $432(20.2)$ & $475(20.8)$ \\
\hline Senior high & $906(20.5)$ & $496(23.2)$ & $410(17.9)$ \\
\hline College or above & $259(5.9)$ & $155(7.2)$ & $104(4.6)$ \\
\hline \multicolumn{4}{|l|}{ Parental income (NT\$ per month) ${ }^{\mathrm{a}}$} \\
\hline$\leq 29999(\leq \mathrm{US} \$ 1154)$ & $483(12.3)$ & $217(11.1)$ & $266(13.5)$ \\
\hline 30000-59999 (US\$ 1154-2308) & $1989(50.7)$ & $932(47.7)$ & $1057(53.7)$ \\
\hline 60000-89999 (US\$ 2308-3462) & $917(23.4)$ & $498(25.5)$ & $419(21.3)$ \\
\hline$\geq 90000(\geq \mathrm{US} \$ 3462)$ & $536(13.7)$ & $309(15.8)$ & $227(11.5)$ \\
\hline \multicolumn{4}{|l|}{ Living at home } \\
\hline Yes & $1989(44.8)$ & $1775(82.6)$ & $214(9.3)$ \\
\hline No & $2455(55.2)$ & $374(17.4)$ & $2081(90.7)$ \\
\hline \multicolumn{4}{|l|}{ Usual riding position } \\
\hline Pillion passenger & $2155(48.3)$ & $1127(52.3)$ & $1028(44.5)$ \\
\hline Operator & $2308(51.7)$ & $1027(47.7)$ & $1281(55.5)$ \\
\hline \multicolumn{4}{|l|}{ Riding experience (years) ${ }^{b}$} \\
\hline$<1$ & $601(26.0)$ & $331(32.2)$ & $270(21.1)$ \\
\hline 1 & $518(22.4)$ & $268(26.1)$ & $250(19.5)$ \\
\hline 2 & $409(17.7)$ & $166(16.2)$ & $243(19.0)$ \\
\hline 3 & $249(10.8)$ & $117(11.4)$ & $132(10.3)$ \\
\hline$\geq 4$ & $531(23.0)$ & $145(14.1)$ & $386(30.1)$ \\
\hline \multicolumn{4}{|c|}{ Frequency of usual alcohol consumption per month } \\
\hline 0 & $3340(75.4)$ & $1593(74.0)$ & $1747(76.7)$ \\
\hline 1 & $804(18.2)$ & $441(20.5)$ & $363(15.9)$ \\
\hline$\geq 2$ & $285(6.4)$ & $118(5.5)$ & $167(7.3)$ \\
\hline \multicolumn{4}{|l|}{ Motorcycle crashes prior to the study } \\
\hline Yes & $1833(41.1)$ & $889(41.3)$ & $944(40.9)$ \\
\hline No & $2630(58.9)$ & $1265(58.7)$ & $1365(59.1)$ \\
\hline
\end{tabular}

a The exchange rate of US\$ to NT\$ was approximately 1:26 at the time of the initial assessment.

${ }^{\mathrm{b}}$ Operators only.

participating in the initial assessment according to selected baseline characteristics. Of these students, $1833(41.1 \%)$ had experienced a motorcycle crash prior to the study. Distributions of all characteristics but motorcycle crashes prior to the study significantly differed between Taipei and Hualien students.

Table 2 presents distributions of the number of motorcycle crashes, time duration from the last crash to the end of the study, and severity of the most serious crash during the study period. Of 4463 students participating in the ini- tial assessment, $3252(72.9 \%)$ experienced no crashes, 825 (18.5\%) had one crash, 265 (5.9\%) two crashes, and 121 $(2.7 \%)$ three or more crashes. Five hundred and thirteen students (11.5\%) were involved in their last crashes 0-6 months prior to the end of this study, $411(9.2 \%)$ in 6-12 months prior to the end of the study, and $287(6.4 \%)$ in $12-18$ months prior to the end of the study. Over the study period, of the $438(9.9 \%)$ students who had experienced the most serious crash injury, 6 had died and could not provide risk-taking information in the third follow-up assessment. Distributions 
Table 2

Number of motorcycle crashes, time elapse since the last crash, and severity of the most serious crash occurring in the study period among 2154 junior college students in Taipei and 2309 in Hualien, Taiwan

\begin{tabular}{|c|c|c|c|}
\hline Characteristic & $\begin{array}{l}\text { Total } \\
(n=4463) \\
(\text { no. }(\%))\end{array}$ & $\begin{array}{l}\text { Taipei } \\
(n=2154) \\
(\text { no. }(\%))\end{array}$ & $\begin{array}{l}\text { Hualien } \\
(n=2309) \\
(\text { no. }(\%))\end{array}$ \\
\hline \multicolumn{4}{|c|}{ Number of motorcycle crashes } \\
\hline 0 & $3252(72.9)$ & $1428(66.3)$ & $1824(79.0)$ \\
\hline 1 & $825(18.5)$ & $474(22.0)$ & $351(15.2)$ \\
\hline 2 & $265(5.9)$ & $165(7.7)$ & $100(4.3)$ \\
\hline$\geq 3$ & $121(2.7)$ & $87(4.0)$ & $34(1.5)$ \\
\hline \multicolumn{4}{|c|}{ Time elapse since last crash (months) } \\
\hline No crash & $3252(72.9)$ & $1428(66.3)$ & $1824(79.0)$ \\
\hline $0-6$ & $513(11.5)$ & $352(16.3)$ & $161(7.0)$ \\
\hline $6-12$ & $411(9.2)$ & $267(12.4)$ & $144(6.2)$ \\
\hline $12-18$ & $287(6.4)$ & $107(5.0)$ & $180(7.8)$ \\
\hline \multicolumn{4}{|c|}{ Severity of the most serious crash } \\
\hline No crash & $3252(72.9)$ & $1428(66.3)$ & $1824(79.0)$ \\
\hline No injury & $773(17.3)$ & $488(22.7)$ & $285(12.3)$ \\
\hline Injury & $438(9.9)$ & $238(11.0)$ & $200(8.7)$ \\
\hline
\end{tabular}

of the three crash experience measures significantly differed between Taipei and Hualien students.

Table 3 presents changes in risk-taking scores from the initial to the third follow-up assessment among 2812 students who completed the two risk-taking assessments. Risk-taking scores increased over the study period among all students but particularly in Hualien students. Without taking other variables into account, positive changes in risk-taking scores among Taipei students were significantly associated with a younger age, less-frequent alcohol consumption, and the lack of a motorcycle crash prior to the study. Among Hualien students, positive score changes were significantly or marginally associated with a younger age, higher parental incomes, and a shorter time having elapsed since the last crash. Furthermore, it was noted that the relationships of crash experience measures to changes in risk-taking scores between Taipei and Hualien students qualitatively differed. Therefore, two separate linear mixed models were respectively applied to Taipei and Hualien students.

Results of the linear mixed model analysis treating risk-taking scores as an outcome variable among Taipei students are shown in Table 4. In all three models, baseline characteristics significantly associated with risk-taking scores are accounted for, and these include age in years and frequency of alcohol consumption. At the time of the initial assessment, students who had experienced a motorcycle crash prior to the study had a risk-taking score 2.0 points (95\% CI $=1.6-2.3$ ) higher than those who had not. Among students who had no experience of a motorcycle crash, risk-taking scores increased by 8.4 points $(95 \%$ $\mathrm{CI}=4.4-12.4)$ from the initial to the third follow-up assessment. The increase was estimated to be 0.3 points lower if students had prior crash experience; however, this result was not statistically significant. As shown in Model I, com- pared with students who had no crash in the study period, those who had a greater number of motorcycle crashes during the study period had higher risk-taking scores at the initial assessment; however, their risk-taking scores did not significantly increase over the study period. Results from Model II show that, compared with students who did not experience a motorcycle crash during the study period, those whose last crash occurred 0-6 months, 6-12 months, and 12-18 months prior to the end of the study had risk-taking scores at the initial assessment of 1.0, 0.4, and 0.2 points higher, respectively. Over the study period, differences in the change of risk-taking scores between students in each of these three groups and those who had no crash during the study were $0.2,0.0$, and 0.3 points, respectively; none of these differences was statistically significant. As shown in Model III, compared with students who had no crash in the study period, risk-taking scores at the initial assessment among those with non-injurious and injurious crashes were 0.5 and 0.9 points higher, respectively. Score changes at the third follow-up assessment from the initial assessment in the two groups were 0.1 and 0.2 points higher, respectively; none of the differences was statistically significant.

In the three models for Hualien students (Table 5), baseline characteristics significantly associated with risk-taking scores, such as age, alcohol consumption, and parental income, are accounted for. At the initial assessment, students who had experienced a motorcycle crash prior to the study had a risk-taking score 2.0 points $(95 \% \mathrm{CI}=1.6-2.4)$ higher than those who had not. Among the students who had had no experience of a motorcycle crash, risk-taking scores increased by 4.6 points $(95 \% \mathrm{CI}=0.6-8.6$ ) from the initial to the third follow-up assessment. The increase was estimated to be 0.3 points higher for students with prior crash experience; however, this result was not statistically significant. Compared with students who had no crash during the study, risk-taking scores of those who had three or more motorcycle crashes during the study period increased by 1.5 points (95\% CI $=0.1-2.9$ ) from the initial to the third follow-up assessment, as shown in Model I; in addition, the risk-taking scores of those whose last crash occurred 0-6 months prior to the end of the study increased by 1.1 points $(95 \% \mathrm{CI}=$ 0.2-2.0), as shown in Model II. Results from Model III show that students with any level of crash severity during the study period did not have significantly different risk-taking scores at the initial assessment from those who had no crash during that period, nor did they have significantly different changes in risk-taking scores from the initial to the third follow-up assessments.

\section{Discussion}

This study indicates that young people with crash experience had higher risk-taking scores at the time of the initial assessment (in other words, risk taking was a risk factor for 
Table 3

Changes (mean \pm standard deviation) in risk-taking scores from the initial to the third follow-up assessment among 2812 junior college students in Taipei and Hualien, Taiwan

\begin{tabular}{|c|c|c|c|c|}
\hline \multirow[t]{2}{*}{ Characteristic } & \multicolumn{2}{|c|}{ Taipei $(n=1739)$} & \multicolumn{2}{|c|}{ Hualien $(n=1073)$} \\
\hline & Mean \pm S.D. & $P$-value ${ }^{\mathrm{a}}$ & Mean \pm S.D. & $P$-value ${ }^{\mathrm{a}}$ \\
\hline \multicolumn{5}{|l|}{ Age at the initial assessment (years) } \\
\hline 17 & $1.56 \pm 3.92$ & 0.000 & $2.16 \pm 3.94$ & 0.008 \\
\hline 18 & $0.91 \pm 3.99$ & & $1.60 \pm 3.66$ & \\
\hline 19 & $0.40 \pm 4.07$ & & $1.87 \pm 4.75$ & \\
\hline$\geq 20$ & $0.64 \pm 3.62$ & & $0.65 \pm 4.03$ & \\
\hline \multicolumn{5}{|l|}{ Gender } \\
\hline Female & $0.84 \pm 2.81$ & 0.486 & $1.63 \pm 2.73$ & 0.909 \\
\hline Male & $0.97 \pm 5.56$ & & $1.60 \pm 6.09$ & \\
\hline \multicolumn{5}{|l|}{ Father's education } \\
\hline Elementary or below & $1.00 \pm 3.87$ & 0.849 & $1.70 \pm 3.35$ & 0.928 \\
\hline Junior high & $0.81 \pm 3.70$ & & $1.66 \pm 3.85$ & \\
\hline Senior high & $0.88 \pm 3.93$ & & $1.54 \pm 4.33$ & \\
\hline College or above & $0.82 \pm 4.53$ & & $1.52 \pm 5.11$ & \\
\hline \multicolumn{5}{|l|}{ Mother's education } \\
\hline Elementary or below & $0.87 \pm 3.69$ & 0.977 & $1.64 \pm 3.53$ & 0.920 \\
\hline Junior high & $0.83 \pm 4.21$ & & $1.54 \pm 3.83$ & \\
\hline Senior high & $0.88 \pm 4.47$ & & $1.54 \pm 5.15$ & \\
\hline College or above & $1.01 \pm 3.72$ & & $1.92 \pm 5.42$ & \\
\hline \multicolumn{5}{|l|}{ Parental income (NT\$ per month) ${ }^{\mathrm{b}}$} \\
\hline$\leq 29999(\leq$ US\$ 1154$)$ & $1.00 \pm 4.69$ & 0.710 & $0.80 \pm 4.17$ & 0.034 \\
\hline 30000-59999 (US\$ 1154-2308) & $0.90 \pm 3.47$ & & $1.75 \pm 3.77$ & \\
\hline 60000-89999 (US\$ 2308-3462) & $0.88 \pm 4.28$ & & $1.43 \pm 4.15$ & \\
\hline$\geq 90000(\geq \mathrm{US} \$ 3462)$ & $0.61 \pm 4.54$ & & $2.17 \pm 5.16$ & \\
\hline \multicolumn{5}{|l|}{ Living at home } \\
\hline Yes & $0.92 \pm 4.14$ & 0.403 & $1.46 \pm 4.60$ & 0.565 \\
\hline No & $0.72 \pm 3.18$ & & $1.65 \pm 3.96$ & \\
\hline \multicolumn{5}{|l|}{ Usual riding position } \\
\hline Pillion passenger & $0.96 \pm 3.03$ & 0.347 & $1.58 \pm 2.97$ & 0.708 \\
\hline Operator & $0.79 \pm 4.86$ & & $1.66 \pm 4.90$ & \\
\hline \multicolumn{5}{|l|}{ Riding experience (years) ${ }^{\mathrm{c}}$} \\
\hline$<1$ & $1.00 \pm 3.80$ & 0.565 & $2.45 \pm 4.81$ & 0.208 \\
\hline 1 & $0.94 \pm 4.67$ & & $1.79 \pm 4.56$ & \\
\hline 2 & $0.59 \pm 5.26$ & & $1.40 \pm 4.25$ & \\
\hline 3 & $0.65 \pm 5.16$ & & $1.51 \pm 5.75$ & \\
\hline$\geq 4$ & $0.38 \pm 6.46$ & & $1.16 \pm 5.19$ & \\
\hline \multicolumn{5}{|c|}{ Frequency of usual alcohol consumption per month } \\
\hline 0 & $1.05 \pm 3.46$ & 0.000 & $1.66 \pm 3255$ & 0.199 \\
\hline 1 & $0.72 \pm 4.88$ & & $1.75 \pm 5.88$ & \\
\hline$\geq 2$ & $-0.91 \pm 6.37$ & & $0.87 \pm 5.95$ & \\
\hline \multicolumn{5}{|l|}{ Past motorcycle crash history } \\
\hline Yes & $0.52 \pm 4.68$ & 0.001 & $1.61 \pm 3.22$ & 0.916 \\
\hline No & $1.13 \pm 3.43$ & & $1.63 \pm 5.11$ & \\
\hline \multicolumn{5}{|c|}{ Number of motorcycle crashes in the study period } \\
\hline 0 & $0.88 \pm 3.74$ & 0.805 & $1.52 \pm 3.91$ & 0.147 \\
\hline 1 & $0.97 \pm 4.25$ & & $1.72 \pm 4.41$ & \\
\hline 2 & $0.93 \pm 4.10$ & & $1.72 \pm 3.94$ & \\
\hline$\geq 3$ & $0.49 \pm 5.81$ & & $3.16 \pm 4.49$ & \\
\hline \multicolumn{5}{|c|}{ Time elapse since last crash in the study period (months) } \\
\hline No crash & $0.88 \pm 3.74$ & 0.167 & $1.52 \pm 3.91$ & 0.056 \\
\hline $0-6$ & $0.97 \pm 4.79$ & & $2.39 \pm 4.10$ & \\
\hline $6-12$ & $0.53 \pm 4.03$ & & $1.76 \pm 4.29$ & \\
\hline $12-18$ & $1.60 \pm 4.02$ & & $1.20 \pm 4.58$ & \\
\hline \multicolumn{5}{|c|}{ Severity of the most serious crash in the study period } \\
\hline No crash & $0.88 \pm 3.74$ & 0.974 & $1.52 \pm 3.91$ & 0.429 \\
\hline No injury & $0.88 \pm 4.62$ & & $1.87 \pm 4.38$ & \\
\hline Injury & $0.94 \pm 4.01$ & & $1.80 \pm 4.25$ & \\
\hline
\end{tabular}

a The exchange rate of US\$ to NT\$ was approximately 1:26 at the time of the initial assessment.

${ }^{\mathrm{b}}$ Operators only.

${ }^{\mathrm{c}}$ One-way ANOVA test was used. 
Table 4

Results of linear mixed model analysis: adjusted relative differences (RD) and 95\% confidence intervals (CI) for risk-taking scores related to crash history prior to the study, number of motorcycle crashes, time elapse since last crash, and severity of the most serious crash in the study period, and other factors among 2154 junior college students in Taipei, Taiwan

\begin{tabular}{|c|c|c|c|c|c|c|}
\hline \multirow[t]{2}{*}{ Characteristic } & \multicolumn{2}{|c|}{ Model $\mathrm{I}^{\mathrm{a}}$} & \multicolumn{2}{|c|}{ Model $\mathrm{II}^{\mathrm{a}}$} & \multicolumn{2}{|c|}{ Model III ${ }^{\mathrm{a}}$} \\
\hline & RD & $95 \% \mathrm{CI}$ & $\mathrm{RD}$ & $95 \% \mathrm{CI}$ & RD & $95 \% \mathrm{CI}$ \\
\hline Crashes prior to the study (yes/no) & 2.0 & $1.6-2.3$ & 2.0 & $1.6-2.4$ & 2.0 & $1.6-2.4$ \\
\hline Time (third follow-up/initial) & 8.4 & $4.4-12.4$ & 8.5 & $4.5-12.5$ & 8.4 & $4.4-12.4$ \\
\hline Crashes prior to the study $\times$ time & -0.3 & $-0.7-0.1$ & -0.3 & $-0.7-0.1$ & -0.4 & $-0.7-0.1$ \\
\hline \multicolumn{7}{|l|}{ Number of crashes in the study period } \\
\hline 0 (reference group) & 0.0 & - & - & - & - & - \\
\hline 1 & 0.5 & $0.0-0.9$ & - & - & - & - \\
\hline 2 & 0.6 & $0.0-1.3$ & - & - & - & - \\
\hline$\geq 3$ & 1.8 & $0.8-2.7$ & - & - & - & - \\
\hline \multicolumn{7}{|c|}{ Number of crashes in the study period $\times$ time } \\
\hline $1 \times$ time & 0.2 & $-0.3-0.6$ & - & - & - & - \\
\hline $2 \times$ time & 0.1 & $-0.6-0.7$ & - & - & - & - \\
\hline$\geq 3 \times$ time & -0.4 & $-1.3-0.5$ & - & - & - & - \\
\hline \multicolumn{7}{|c|}{ Time elapse since last crash in the study period (months) } \\
\hline No crash (reference group) & & & 0.0 & - & & \\
\hline $0-6$ & - & - & 1.0 & $0.3-1.7$ & - & - \\
\hline $6-12$ & - & - & 0.4 & $-0.3-1.0$ & - & - \\
\hline $12-18$ & - & - & 0.2 & $-0.6-0.9$ & - & - \\
\hline \multicolumn{7}{|c|}{ Time elapse since last crash in the study period $\times$ time } \\
\hline $0-6 \times$ time & - & - & 0.2 & $-0.4-0.9$ & - & - \\
\hline $6-12 \times$ time & - & - & 0.0 & $-0.6-0.6$ & - & - \\
\hline $12-18 \times$ time & - & - & 0.3 & $-1.0-0.4$ & - & - \\
\hline \multicolumn{7}{|c|}{ Severity of the most serious crash in the study period } \\
\hline No crash (reference group) & - & - & - & - & 0.0 & - \\
\hline No injury & - & - & - & - & 0.5 & $0.1-1.0$ \\
\hline Injury & - & - & - & - & 0.9 & $0.3-1.5$ \\
\hline \multicolumn{7}{|c|}{ Severity of the most serious crash in the study period $\times$ time } \\
\hline No injury $\times$ time & - & - & - & - & 0.1 & $-0.4-0.5$ \\
\hline Injury $\times$ time & - & - & - & - & 0.2 & $-0.4-0.7$ \\
\hline
\end{tabular}

a Adjusted for age (years), age $\times$ time, alcohol consumption (times per month), and alcohol consumption $\times$ time.

the occurrence of motorcycle crashes during the study period); however, crash experience, in terms of its frequency, severity, and time elapsed since the most recent crash, did not significantly change their risk-taking path over the study period, even though its effect somewhat differed between Taipei and Hualien students.

Although additional motorcycle crashes were highly positively correlated with a shorter time elapsed since the last crash, it was not coincident that a high frequency of crash involvement and the latest crash experience were significantly associated with positive changes in risk-taking scores among Hualien students. Nonetheless, further subgroup analysis showed that positive changes in risk-taking scores among students who had three or more crashes occurring in the study period were similar in the two Hualien schools (1.4 versus 1.4), and that positive changes in risk-taking scores among students whose last crash occurred 0-6 months prior to the end of the study differed in the two Hualien schools (1.2 versus 0.1 ). Based on this result, at first glance, a possible explanation is that students who survived many crashes were encouraged to take greater risks over time compared to those who had no crash during the study period. However, the reason would be more convincing if the result had also appeared in Taipei students. Another explanation might be that some physical/social environmental factor(s), specific to Hualien or rural areas, existed to increase the occurrence of motorcycle crashes as well as risk-taking levels in Hualien students. For example, roadside inspections for drinking and driving may be fewer and laws on speeding may be less strictly enforced in rural areas due to less police manpower and larger patrol scopes. Overall, crash experience might not have an independent effect with environmental factors on changes in risk-taking propensity, even when students are involved in more crashes.

As indicated by Jessor (1991), Baumrind (1987), and Hodgdon et al. (1981), risk-taking persistency ensures that crash experience measures are significantly associated with initial scores for risk taking. However, few measures remained significant with changes in risk taking which was unmodified by past experience partly due to the tendency 
Table 5

Results of linear mixed model analysis: adjusted relative differences (RD) and 95\% confidence intervals (CI) for risk-taking scores related to crash history prior to the study, number of motorcycle crashes, time elapse since last crash, and severity of the most serious crash in the study period, and other factors among 2309 junior college students in Hualien, Taiwan

\begin{tabular}{|c|c|c|c|c|c|c|}
\hline \multirow[t]{2}{*}{ Characteristic } & \multicolumn{2}{|c|}{ Model $\mathrm{I}^{\mathrm{a}}$} & \multicolumn{2}{|c|}{ Model II $^{\mathrm{a}}$} & \multicolumn{2}{|c|}{ Model III ${ }^{\mathrm{a}}$} \\
\hline & $\mathrm{RD}$ & $95 \% \mathrm{CI}$ & $\mathrm{RD}$ & $95 \% \mathrm{CI}$ & RD & $95 \% \mathrm{CI}$ \\
\hline Crashes prior to the study (yes/no) & 2.0 & $1.6-2.4$ & 2.0 & $1.6-2.4$ & 2.0 & $1.6-2.4$ \\
\hline Time (third follow-up/initial) & 4.6 & $0.6-8.6$ & 4.6 & $0.6-8.6$ & 4.6 & $0.6-8.6$ \\
\hline Crashes prior to the study $\times$ time & 0.3 & $-0.2-0.7$ & 0.3 & $-0.2-0.7$ & 0.3 & $-0.2-0.7$ \\
\hline \multicolumn{7}{|l|}{ Number of crashes in the study period } \\
\hline 0 (reference group) & 0.0 & - & - & - & - & - \\
\hline 1 & 0.4 & $-0.2-0.9$ & - & - & - & - \\
\hline 2 & 0.5 & $-0.4-1.4$ & - & - & - & - \\
\hline$\geq 3$ & 0.5 & $-1.1-2.1$ & - & - & - & - \\
\hline \multicolumn{7}{|c|}{ Number of crashes in the study period $\times$ time } \\
\hline $1 \times$ time & 0.2 & $-0.3-0.7$ & - & - & - & - \\
\hline $2 \times$ time & 0.0 & $-0.9-0.9$ & - & - & - & - \\
\hline$\geq 3 \times$ time & 1.5 & $0.1-2.9$ & - & - & - & - \\
\hline \multicolumn{7}{|c|}{ Time elapse since last crash in the study period (months) } \\
\hline No crash (reference group) & & & 0.0 & - & & \\
\hline $0-6$ & - & - & -0.1 & $-1.0-0.9$ & - & - \\
\hline $6-12$ & - & - & 0.4 & $-0.7-1.5$ & - & - \\
\hline $12-18$ & - & - & -0.5 & $-0.6-0.4$ & - & - \\
\hline \multicolumn{7}{|c|}{ Time elapse since last crash in the study period $\times$ time } \\
\hline $0-6 \times$ time & - & - & 1.1 & $0.2-2.0$ & - & - \\
\hline $6-12 \times$ time & - & - & 0.5 & $-0.5-1.5$ & - & - \\
\hline $12-18 \times$ time & - & - & 0.3 & $-0.6-1.1$ & - & - \\
\hline \multicolumn{7}{|c|}{ Severity of the most serious crash in the study period } \\
\hline No crash (reference group) & - & - & - & - & 0.0 & - \\
\hline No injury & - & - & - & - & 0.4 & $-0.2-1.0$ \\
\hline Injury & - & - & - & - & 0.4 & $-0.2-1.1$ \\
\hline \multicolumn{7}{|c|}{ Severity of the most serious crash in the study period $\times$ time } \\
\hline No injury $\times$ time & - & - & - & - & 0.2 & $-0.4-0.8$ \\
\hline Injury $\times$ time & - & - & - & - & 0.3 & $-0.3-1.0$ \\
\hline
\end{tabular}

a Adjusted for age (years), age $\times$ time, alcohol consumption (times per month), alcohol consumption $\times$ time, monthly parental income $(\leq \mathrm{NT} \$ 29,999$; NT\$ 30,000-59,999; NT\$ 60,000-89,999; $\geq$ NT\$ 90,000), and monthly parental income $\times$ time.

among young people to use risk taking as a means to fulfill their psychological needs such as gaining peer acceptance, establishing autonomy from parents, affirming maturity, repudiating the norms and values of conventional authority, building self-esteem, and enhancing competence. In addition, our findings also substantiate the conjecture from Chilton (1977) that health-promotion education only using negative consequences of motor-vehicle crashes intended to reduce high risk-taking behavior among young persons might not easily succeed, even if these educational materials do increase risk perception (Rutter et al., 1998; Matthews and Moran, 1986; Sevenson et al., 1985). It appears that an effective health-promotion strategy, particularly for young people, ought to take into account their physical and psychological needs while increasing their awareness of negative consequences.

There are some comments about the risk-taking scale. First, the average risk-taking score was low because young people typically engaged in only a few rather than all risk-taking behaviors as listed in the questionnaire. The possibility that the score for a student may be driven by one or two items is not of great concern in the study because whichever risk-taking behavior he/she engaged in represents certain degree of underlying overall propensity for taking a risk. In other words, different items may be comparable in reflecting an individually personal trait of taking a risk. This is evidenced by the result of the factor analysis. Second, despite that the 14 items of the risk-taking scale were provided to measure a latent variable (i.e. risk-taking levels or propensity) rather than specific risk-taking behaviors (e.g. risky driving practices) for a student, the responsiveness of the risk-taking scale might be poor due to that 2 driving-related items and 12 non-driving items were included in the scale. If true, the scale was inefficient to detect the risk-taking changes over the study period. Third, risk taking characterized by the 14 items might not be appropriate nowadays, since the culture of Taiwanese society has changed rapidly in recent years. For example, video game playing by minors at arcades is no longer prohibited and the use of contraceptive devices during sex has become more common among young people.

There are several limitations to this study. First, as indicated in another study (Lin et al., in press), non-injurious crashes were possibly incompletely reported. One may 
speculate that students who had higher risk taking under-reported motorcycle crashes over the study period; however, the data of 0.62 crashes per person reported by the $10 \%$ of students who had the most highest risk-taking levels and 0.42 by the counterpart does not support the speculation. Even if there was under-reporting among risk-takers, it was not likely to invalidate our conclusion. This is because we were analyzing the change in risk taking and how it was related to crash experience, provided that the risk-taking score of under-reporters did not change more drastically over time than those who did not under-report. Furthermore, characteristics of students lost to follow-up are likely to have differed from those of students remaining in the study. Of all students who had not graduated from the college by the end of the study, those who did not participate in the third follow-up assessment were more likely to have had higher initial risk-taking scores, a crash history prior to the study, or severe injuries resulting in disability in a crash. Accordingly, the positive effect of crash experience on changes in risk taking would have been underestimated. Second, immediate changes in risk taking after crash involvement were not evaluated in this study. It is possible that effects of a crash experience on changes in risk taking decreased rapidly to a certain level over the study period. Finally, caution is needed when generalizing the results of this study. For example, subjects in this study were limited to older adolescents, and thus the effect of crash experience on changes in risk taking among young adolescents or children may differ and thus require further research.

\section{Acknowledgements}

This study was supported by funding from the National Science Council, Executive Yuan, Republic of China (grants NSC 84-2331-b-016-092 and NSC 88-2314-b-039-036).

\section{References}

Alexander, C.S., Ensminger, M.E., Somerfield, M.R., 1992. Behavioral risk factors for injury among rural adolescents. Am. J. Epidemiol. 136, 673-685.

Baumrind, D., 1987. A developmental perspective on adolescent risk taking in contemporary America. In: Irwin, C.E. (Ed.), Adolescent Social Behavior and Health. New Directions for Child Development. Social and Behavioral Series, No. 37, Fall. Jossey-Bass, San Francisco, pp. 93-125.

Begg, D.J., Langley, J.D., Williams, S.M., 1999. A longitudinal study of lifestyle factors as predictors of injuries and crashes among young adults. Accid. Anal. Prev. 31, 1-11.

Begg, D.J., Langley, J.D., Redder, A.I., 1994. Motorcycle crashes in New Zealand resulting in death and hospitalization. I. Introduction, methods and overview. Accid. Anal. Prev. 26, 157-164.

Brown, R.C., Sanders, J.M., Schonberg, S.K., 1986. Driving safety and adolescent behavior. Pediatrics 77, 603-607.

Chilton, L.A., 1977. Potential benefit vs. risk of current attempts in health education among adolescents. J. Pediatr. 90, 163-164.

Cnaan, A., Laird, N.M., Slasor, P., 1997. Using the general linear mixed model to analyse unbalanced repeated measures and longitudinal data. Stat. Med. 16, 2349-2380.
Diggle, P.J., Liang, K.Y., Zeger, S.L., 1994. The Analysis of Longitudinal Data. Oxford University Press, New York.

Ding, S.L., Wang, J.D., Chen, K.T., 1993. Estimate of case fatality rate and incidence rate of traffic injury in Taiwan-analysis of 4,329 victims at a medical center. J. Formos. Med. Assoc. 92, S76-S81.

Greydanus, D.E., 1987. Risk-taking behaviors in adolescence. JAMA 258, 2110.

Hill, P.S., Jamieson, B.D., 1978. Driving offenders and the defensive driving course-an archival study. J. Psychol. 98, 117-127.

Hodgdon, J.D., Bragg, B.W.E., Finn, P., 1981. Youth Driver Risk-Taking Research: The State of the Art. HS-805-967. National Highway Traffic Safety Administration, Washington, DC, March.

Irwin, C.E., Millstein, S.G., 1986. Biopsychosocial correlates of risk-taking behaviors during adolescence. J. Adolesc. Health 7, 82S-96.

Jelalian, E., Alday, S., Spirito, A., 2000. Adolescent motor vehicle crashes: the relationship between behavioral factors and self-reported injury. J. Adolesc. Health 27, 84-93.

Jessor, R., 1991. Risk behavior in adolescence: a psychosocial framework for understanding and action. J. Adolesc. Health 12, 597-605.

Jonah, B.A., 1986. Accident risk and risk-taking behaviour among young drivers. Accid. Anal. Prev. 18, 255-271.

Liberatti, C.L., Andrade, S.M., Soares, D.A., 2001. The new Brazilian traffic code and some characteristics of victims in southern Brazil. Injury Prev. 7 (3), 190-193.

Lin, M.-R., Chang, S.H., Pai, L., Keyl, P.M. A longitudinal study of risk factors for motorcycle crashes among junior college students in Taiwan. Accid. Anal. Prev., in press.

Matthews, M., Moran, A., 1986. Age difference in male drivers' perception of accident risk: the role of perceived driving ability. Accid. Anal. Prev. 18, 299-313.

Mickey, R.M., Greenland, S., 1989. The impact of confounder selection criteria on effect estimation. Am. J. Epidemiol. 129, 125-137.

Ministry of Communication and Transportation, 1993. Annual report of transportation and communication in 1992. Executive Yuan, Taipei, ROC.

Mohan, D., Bawa, P.S., 1985. An analysis of road traffic fatalities in Delhi, India. Accid. Anal. Prev. 17, 33-45.

Nunnally, J.C., Bernstein, I.H., 1994. Psychometric Theory, third ed. McGraw-Hill, New York.

Pang, T.Y., Radin Umar, R.S., Azhar, A.A., Megat Ahmad, M., Mohad Nasir, M.T., Harwant, S., 2000. Accident characteristics of injured motorcyclists in Malaysia. Med. J. Malays. 55 (2), 45-50.

Perloff, L.S., Fetzer, B.K., 1986. Self-other judgments and perceived vulnerability to victimization. J. Pers. Soc. Psychol. 50, 502-510.

Preusser, D.F., Ulmer, R.G., Adams, J.R., 1976. Driver record evaluation of a drinking driver rehabilitation program. J. Safety Res. 8, 98-105.

Ray, H.W., Weaver, J.K., Brink, J.R., 1982. Safe Performance Secondary School Education Curriculum. National Highway Traffic Safety Administration, Washington, DC.

Rutter, D.R., Quine, L., Albery, I.P., 1998. Perceptions of risk in motorcyclists: unrealistic optimism, relative realism and predictions of behaviour. Br. J. Psychol. 89, 681-696.

Schootman, A., Fuortes, L.J., Zwerling, C., 1993. Safety behavior among Iowa junior high and high school students. Am. J. Public Health 83, $1628-1630$.

Sells, C.W., Bhon, R.W., 1996. Morbidity and mortality among US adolescents: an overview of data and trends. Am. J. Public Health 86, 513-519.

Sevenson, O., Fischnoff, B., MacGregor, D., 1985. Perceived driving safety and seatbelt usage. Accid. Anal. Prev. 17, 119-133.

Shaoul, J., 1975. The Use of Accidents and Traffic Offenses as Criteria for Evaluating Courses in Driver Education. University of Salford Press, Salford, England.

Slap, G.B., Chaudhuri, S., Corters, D.F., 1991. Risk factors for injury during adolescence. J. Adolesc. Health 12, 263-268.

Stevens, J., 1992. Applied Multivariate Statistics for the Social Sciences, second ed. Lawrence Erlbaum Associates, Hillsdale, NJ. 
Swaddiwudhipong, W., Nguntra, P., Mahasakpan, P., Koonchote, S., Tantriratna, G., 1994. Epidemiologic characteristics of drivers, vehicles, pedestrians and road environments involved in road traffic injuries in rural Thailand. SE Asian J. Trop. Med. Public Health 25 (1), 37-44.

Tarter, R.E., Alterman, A.I., Edwards, K.L., 1985. Vulnerability to alcoholism in men: a behavior-genetic perspective. J. Stud. Alcohol 46, 329-356.
Tokin, R.S., 1987. Adolescent risk-taking behavior. J. Adolesc. Health 8, 213-220.

Weinstein, N.D., Klein, W.M., 1996. Unrealistic optimism: present and future. J. Soc. Clin. Psychol. 15, 1-8.

Zuckerman, M., 1990. The psychophysiology of sensation seeking. J. Pers. 58, 313-341. 